\title{
LA PSICOTERAPIA COMO CONVERSACIÓN CONTEMPLATIVA
}

\section{PSYCHOTHERAPY AS CONTEMPLATIVE CONVERSATION}

\author{
María Teresa Miró \\ Universidad de La Laguna , Facultad de Psicología. Tenerife. Islas Canarias, España \\ ORCID: https://orcid.org/0000-0002-0059-7703
}

Cómo referenciar este artículo/How to reference this article:

Miró, M. T. (2020). La psicoterapia como conversación contemplativa. Revista de Psicoterapia, 31(116), 133-145. https://doi.org/10.33898/rdp.v31i116.411

\section{Resumen}

Se presenta la visión de la psicoterapia como una conversación contemplativa. Como preliminar a la conversación contemplativa se propone el Entrenamiento en Atención Consciente y se ofrece un modelo en 30 sesiones (EAC/ULL). Se plantea la naturaleza ontológica de la conversación en la vida humana y se ofrecen ejes para comprender su profundidady alcance. También se aborda la investigación neurocientífica actual para acercarse al tema de la contemplación. Por último, se abordan cuestiones prácticas para utilizar este enfoque en la sesión terapéutica.

Palabras clave: neurociencia contemplativa, contemplación, conversación terapéutica.

\begin{abstract}
The conception of psychotherapy as contemplative conversation is presented. As preliminary request training in Conscious Attention is required, a 30 session model of how to do it is offered, the EAC/ULL. The ontological nature of conversation in human life is explored and tools are offered to reach out for its depth and amplitude. To address the topic of contemplation, neuroscientific research is reviewed. Likewise, practical implications for the therapeutic sessions are derived from this approach.

Keywords: contemplative neuroscience, contemplation, therapeutic conversation.
\end{abstract}


(...) el psicoanálisis no es una ciencia en el mismo sentido que la física y la química, sino una forma secular de espiritualidad (Safran, 2003, p. 2).

\section{Introducción}

Conviene empezar por el contexto:

Cuando hace unos meses, el director de esta revista, Luís Ángel Saúl, me habló de la idea de hacer un monográfico sobre la conversación en la psicoterapia, me sentí inmediatamente atraída por el proyecto. Me compremetí con él a enviarle un artículo con este título. Cuando adquirí ese compromiso, yo no pensaba que habría algo que desviaría mi atención de este tema completamente. Este algo es la COVID-19.

La decana de mi Facultad de Psicología y Logopedia de la ULL, Ma Ángeles Alonso, me llamó para pedir mi colaboración en una página sobre el coronavirus, cuyo propósito era no sólo informar sobre el virus, sino también ofrecer recursos para paliar la situación entre los sanitarios y también la población en general. En concreto, se me pedía colaborar ofreciendo algún remedio ante la ansiedad y la depresión. Le dije que sin problemas, que iba a grabar una serie de audios para entrenar la Atención Consciente como vehículo para canalizar las energias de la conciencia y salir de la crisis. Mi propia atención se centró en la tarea.

Este entrenamiento está hoy en día disponible en 30 sesiones breves de unos 10 minutos, en la sección Recursos para la Población General, de la página www.

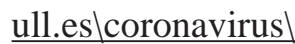

\section{El Entrenamiento en Atención Consciente de la Universidad de La Laguna (EAC/ULL)}

Aunque el programa está en internet y se puede consultar libremente, haré una breve descripción en el contexto de este artículo, por dos razones. Primera, porque el Entrenamiento en Atención Consciente constituye un preliminar para la conversación contemplativa. El programa proporciona un mapa de la conciencia que resulta útil tanto para la práctica formal como para la informal. Explica cómo se puede trabajar con las conciencias sensoriales, que son la ventana a la percepción exterior, y la conciencia corpórea, ventana al interior, más la conciencia mental y la conciencia interpersonal. Con un mapa así es mucho más fácil trabajar con los estados mentales negativos y también con los positivos. El propósito del programa es que el practicante adopte una práctica, formal e informal, de la Atención Consciente en su vida.

La primera tarea era obvia: ofrecer formas rápidas y efectivas de "traer la atención a casa” como dicen mis colegas del Hospital La Paz en Madrid quienes, liderados por Beatriz Rodriguez Vega, han puesto un programa parecido al EAC/ ULL. La primera sesión de este programa se titula "Una pausa para la conciencia”, con instrucciones precisas. Las siguientes 3 sesiones se dedican a informar sobre el estrés, junto con saber qué hacer para relajarse de manera rápida y eficaz. 
Después se explica la práctica fundamental y se dan instrucciones para construirse un ricón sagrado.

La práctica fundamental se describe a partir de 3 compromisos que el practicante adquiere consigo mismo. Estos compromisos son:

1) Quietud corpórea. Incluye: saber enraízarse en la postura, saber sentir las sensaciones del contorno del cuerpo. Entender el papel de la postura corpórea en el trabajo con la Atención Consciente. Todos estos elementos resultan útiles a la hora de trabajar con la percepción interna del propio cuerpo.

2) Familiarización con la atención focalizada de la respiración sentida en un soporte preciso y a mano. Aquí hay un aspecto muy sútil, que yo aprendí de mi maestra, la lama Tashi. Se trata de la tendencia a agarrar el soporte. El gesto de agarrar resulta contrario al tipo de atención pasiva que se persigue con la práctica.

3) Retornar al soporte. Soltar la distracción. Percepción de cambios y conflictos atencionales. Trabajo con la actitud hacia las propias lagunas en la atención. Amabilidad y cariño.

El objetivo fundamental de esta práctica es ayudar al practicante a estabilizar la atención. A la vez, ayuda a comprender la naturaleza de la conciencia, la naturaleza del hacerse consciente, el darse cuenta. La cuestión aquí es que la conciencia normalmente llega tarde. Dice Zambrano (1958/1998):

A menudo ocurre, tanto en la vida personal como en la historia, que sólo en ciertos momentos excepcionales los hechos corresponden con los deseos. Realmente, lo que caracteriza la experiencia humana es exactamente la doble necesidad que subyace a toda acción: por un lado, requerida por la circunstancia, el hombre debe afrontar el desafío que la circunstancia le plantea continuamente, y al que debe responder aun a costa de ser aniquilado; por otra parte, debe obedecer su propia condición interna. Precisamente en eso reside la tragedia de la experiencia humana: todo hombre se conoce a sí mismo, incluso antes de pensar, mientras va haciendo y realizando; sólo conoce después de haber actuado. Cuando hace lo que más responde a sus pasiones, a sus anhelos, lo hace sin saber por qué lo está haciendo (pp. 62-63).

Con su lucidez acostumbrada, Zambrano da en la diana de la necesidad de poder llegar a observar la experiencia a medida que sucede. En términos clásicos, esto equivale a poder sentarse en el asiento del testigo.

Volviendo a la dinámica del entrenamiento: Durante las próximas sesiones, la tarea del practicante es practicar. La repetición es la clave de la práctica. Esto es lo que la persistencia del ritual, que son los raíles sin los cuales la cultura no existiría, nos enseña. La práctica es una ventana en la que lo que importa es que te importe, como dice Hokusai. Importa y mucho, cómo hacemos lo que hacemos en la práctica. Se requiere repetir una secuencia que te ayude a verte haciendo lo que haces. 
Cuando se consigue un poco de estabilidad en la concentración de la atención en la vivencia del momento presente, la vida comienza a cambiar. Entonces, se hace necesario disponer de un mapa con el que ordenar el pequeño caos de nuevas sensaciones internas y externas, que se empieza a experimentar, como correlato de la práctica. Es un hecho fácil de comprobar si se está dispuesto a comprometerse a practicar unos 10 o 15 minutos diarios, si es dos veces al día, mejor. La construcción del mapa requiere, como es natural, ir descubriendo territorios, los del propio cuerpo y la propia mente. En esta fase, la escritura terapéutica puede ayudar.

A continuación, se aborda en más detalle la organización de la conciencia, el mapa de la conciencia. Ésta se aborda a partir de 4 cuadrantes, como ha hecho Siegel (2018):

Primer cuadrante: La 5 conciencias sensaroriales.

Segundo cuadrante: La conciencia corpórea (interoceptiva y propioceptiva).

Tercer cuadrante: La conciencia mental (operaciones vs. contenidos mentales).

Cuanto cuadrante: La conciencia interpersonal (estados mentales complejos).

Como ya indiqué antes, este programa está disponible en la web de la ULL dedicada al coronavirus. Una crisis que lo va a cambiar todo y, tal vez, también va a hacernos más conscientes de la forma en que participamos en la construcción de las realidades en las que vivimos. La intención que subyace a las 30 grabaciones es que resultaran útiles e inspiradoras a mis colegas, estudiantes, amigos y a todas aquellas personas que pudieran beneficiarse de la práctica.

Desde el punto de vista que se va a defender en este artículo para comprender la psicoterapia como una conversación contemplativa, el Entrenamiento en Atención Consciente resulta un pre-requisito. En otras palabras, para entrar en la fase contemplativa, es necesario contar con cierta capacidad de estabilizar la atención. El recogimiento de la atención es previo a contemplar, como siempre se ha sabido en los contextos religiosos.

Antes de abordar la naturaleza de la mirada contemplativa, plantearemos el tema de la conversación o, mejor dicho, el estatus ontológico de la conversación en la vida humana. Con la ayuda de Maturana, Wittgenstein y Arnau, algo podremos decir sobre este punto.

Después abordaremos la naturaleza de la contemplación, pero no desde un ángulo religioso que es donde la tradición ha conservado las prácticas, sino desde la investigación neurocientífica actual, por un lado, y desde su lado psicoterapéutico, por otro.

Por último, plantearemos la cuestión de ¿qué implicaciones para la práctica en la sesión tiene una concepción de la psicoterapia como una conversación contemplativa? Es decir, para construir la relación terapéutica, por un lado, y para dirigir la sesión, por otro. 


\section{La naturaleza ontológica de la conversación}

La psicoterapia es una conversación. Esto ya lo dejo dicho Freud: la curación por la palabra. Por eso, conviene saber de que tipo de realidad estamos hablando.

La conversación es lenguaje hablado. Nos conduce a la oralidad del lenguaje, que es la condición natural y pristina del lenguaje, de nuestro ser seres lingüísticos, como han enseñado Walter Ong (1984) y Humberto Maturana (1994). Por otro lado, como explica Arnau (2014) en su Manual portátil de Filosofía, Wittgestein es quien abre la puerta al valor terapéutico del lenguaje. Su filosofía se ocupa de trazar los límites entre el sentido y el sinsentido, de determinar el papel del lenguaje en el pensamiento y la vida humana. El autor del Tractatus (Wittgenstein, 1953/2017) tenía la convicción de que lo verdaderamente importante en la vida es inefable. No obstante, estableció también que es la estructura del lenguaje la que determina el modo en que pensamos el mundo (Anau, 2014).

Los significados de las palabras vienen de sus diferentes usos y esos usos no tienen entre si más que un "parecido de familia". El propósito último de su filosofía es terapéutico, a saber, eliminar las cofusiones intelectuales derivadas de una concepción errónea de la naturaleza del lenguaje (Arnau, 2014). Y añade: Precisamente porque pertenecemos a una comunidad lingüística regida por reglas y contamos con criterios colectivos para nuestras experiencias privadas podemos tener un lenguaje que se refiera a esas experiencias.

La conversación es el lugar natural en el que se produce el uso del lenguaje y se crean y recrean los significados. Maturana que ha elaborado una concepción biológica y ontológica del lenguaje sostiene que la conversación es el nicho ecológico natural de los seres humanos. Maturana ha resumido su aportación de un modo suscinto del siguiente modo:

La conversación es la trama de la que está hecha la vida humana y la supervivencia es el fenómeno fundamental. Ello implica que la conservación de la organización y de la adaptación son el mecanismo generativo por el que se conserva dicho fenémeno. El operar de este mecanismo da lugar al aprendizaje, que es observable. La conservación de la congruencia entre la conducta de un organismo y las perturbaciones que el medio ejerce sobre él son:

a) Una condición necesaria de existencia del organismo, implícita en la conservación de la organización y adaptación durante la ontogenia y,

b) El resultado de que el cambio estructural del organismo, con su sistema nervioso incluido, siga siempre un curso determinado por la coincidencia de perturbaciones ambientales y la conservación de la organización y adaptación que, de hecho, constituyen la condición de existencia del organismo.

A continuación, Maturana añade: esto parece una tautología y lo es. En último término es un sistema de ecuaciones con algunas variables: la estructra inicial (el cigoto en un organismo con reproducción sexuada, por ejemplo) y la secuencia de perturbaciones que constituyen el medio efectivo en el que se realiza la ontogenia 
del organismo que, una vez fijadas, determinan una sola solución: la historia individual del organismo en congruencia con el medio (nicho) hasta su muerte (pérdida de su congruencia con el medio).

Poner el acento en el carácter conversacional de la psicoterapia contribuye a clarificar algunas cosas, como su carácter presencial, su inmediatez. Ocurre en el nivel pre-reflectivo, que es también el nivel en el que sucede la conversación en la vida cotidiana. Por eso, la práctica de la Atención Consciente formal (de 3 a 5 minutos), conjuntamente paciente y terapeuta, ayuda a que la sesión se desarrolle en el tiempo real, el de la vida, que es corpórea - versus el tiempo virtual de internet o el tiempo rápido de la conciencia mental. La psicoterapia es un espacio de resonancia afectiva.

Hace 30 años, Guillem Feixas era un joven profesor en la Universidad de Barcelona y yo era una profesora recien incorporada a la Universidad de La Laguna en Tenerife, Islas Canarias. En 1990 coincidimos en Memphis, Tennesse en EE.UU. en el I Congreso de Constructivismo en Psicoterapia, organizado por R. Neimeyer y M. J. Mahoney, de los cuales Guillem Feixas y yo eramos colegas. Cuando Guillem y yo nos conocimos, nos dimos cuenta de que ambos estábamos atravesando el mismo trance: preparar las oposiciones para optar a una plaza de profesor/a titular. Hacía falta escribir un proyecto docente. En los meses siguientes, intercambiamos ideas y material para nuestros respectivos proyectos docente. Ambos nos presentamos a las plazas en 1992, y ambos las obtuvimos. Después, decidimos juntar nuestros proyectos y así nació Aproximaciones a la psicoterapia, una introducción a los tratamientos psicológicos. Este libro se publicó en 1993 y ha estado re-imprimiendose año tras año desde entonces hasta ahora; en este 2020 acaba el contrato con la editorial, de manera que en poco tiempo ya no estará disponible. Éste parece un buen motivo, por tanto, para hacer una reflexión compartida desde la distancia, sobre lo que ha pasado en el campo en estos casi 30 años. Procederé por contraste respecto a lo que creía cuando escribimos el Feixas y Miró (1993).

Después de un par de capitulos introductorios sobre la historia y el concepto de la psicoterapia, el libro seguía una estrutura nítida: presentar lo que pensábamos eran los cinco modelos raíz que estruturaban el campo de las psicoterapias y concluir planteando el problema de la integración de este corpus del saber. Nuestra apuesta venía a ser que con el desarrollo de una psicoterapia científica, nuestra capacidad de alivio del sufrimiento inútil iba a ser más eficiente. En el fondo, esta premisa era el hilo conductor del libro. Pero, en la actualidad, ya no lo veo de este modo. Por cierto, mindfulness no aparece ni una sola vez en el libro. A principios de los años 90 no estaba en el horizonte de la psicoterapia. Pero a partir del año 2000 experimenta un crecimiento exponencial.

Mi visión del objeto de la disciplina también ha cambiado. Ahora soy más partidaria de la “despatologización” y de que, tal vez, sea más útil para el siglo XXI, ver la disciplina como un ámbito espiritual que verla en la estela de los tratamientos médicos. Cuando era joven y quería ser admitida en el club de la psicología clíni- 
ca, tenía más fe en las categorías diagnósticas que ahora, después de los múltiples escándalos con los DSM y la entificación creciente o simple proliferación con usos comerciales (la industria farmacológica) de etiquetas diagnósticas, que contribuyen sobremanera a una lectura abstracta y fría del sufrimiento en las avanzadas sociedades hipertecnologizadas en las que hoy en día vivimos. De Freud, que abobinaba de la bicicleta y de la máquina de escribir por igual, a la vida consumida en las pantallas, hay un trecho muy grande, por lo que se refiere a de qué está hecha la interioridad.

Del inconsciente obsceno de Freud a la higiene mental lingüística de Wittgestein, hay también el paso de una primera a una segunda revolución industrial. La psicoterapia es una práctica cultural, que se desarrolla a lo largo del siglo XX, el siglo del self. Como Eva Illouz argumentó con claridad, junto al derecho contractual y al liberalismo económico, el discurso terapéutico ha jugado un papel central en la constitución del self actual, secularizado y autónomo, que es la herencia de la modernidad (Illouz, 2010).

La psicoterapia como práctica cultural comienza con el impacto cultural del psicoanálisis. En una sociedad en plena ebullición debido a la primera revolución industrial que trajo el automovil y tantos otros cambios, como el sufragio de las mujeres, la consulta del psicoanalista era un lugar seguro en el que poder hablar de la propia biografía, sin ser juzgado moralmente. Ofrecía, por tanto, un espacio alternativo al de la religión tradicional moralizante, que era el espacio en el que se habían instaurado lo que Rieff (1966) llamó las terapias de compromiso, en las cuales engloba aquellas formas tradicionales por medio de las cual se cumplía un ritual para volver a ser integrado en el orden del grupo.

La técnica que Freud instaura, la técnica analítica practicada 3 o 4 veces por semana, ayudaba a las personas a adoptar una actitud distanciada, analítica, hacia su propia experiencia, de modo que, con el tiempo, podían saber lo que les pasa mientras les está pasando. En la práctica, la asociación libre, de un modo similar a como actúa el entrenamiento formal en la Atención Consciente, contribuye a desarrollar la postura del testigo hacia la propia experiencia.

Pero el psicoanálisis era elitista, aún así, gracias al cine y a las industrias editoriales, se hizo muy popular. Los conceptos del inconsciente, los mecanismo de defensa, y, sobretodo, la represión y su papel "patologizante" se introdujeron rápido en el imaginario colectivo. Un par de décadas después, el imaginario colectivo se agrandó con conceptos provinientes de la psicología humanista: desarrollo personal, auto-realización, autenticidad, logro, etc. De todos ellos, sin duda alguna, el concepto estrella fue el de auto-realización.

Como Illouz (2010) ha explicado, la auto-realización funcionó como una categoria social negativa. Es decir, funcionó porque cuando se escucha a los maestros hablar de la auto-realización, uno/a se da cuenta de que no está realizado. En los años 70, proliferaron los talleres de fin de semana de desarrollo personal, en sus múltiples versiones. Durante esta época, la psicoterapia se hizo popular y se hizo para todos, se “democratizó” (Miró, 2018). 
Hoy por hoy, la industria del desarrollo personal o industria de la auto-ayuda mueve millones de euros. Y esta industria, como tantas veces se ha denunciado, contribuye a crear la propia demanda que pretende resolver. Esta industria no es capaz de cuestionar la premisa sobre la que se sustenta, a saber, que tengo algo que mejorar. ¿Qué no seremos originalmente puros, como propone el Budismo?

Con el auge de la psicología positiva y la expansión del movimiento mindfulness en la práctica clínica, algo ha cambiado este sesgo hacía lo negativo que ha dominado el campo de los tratamientos psicológicos desde los años 60 y 70 del siglo pasado. El estudio de las virtudes, así como la práctica del circulo virtuoso de mindfulness, han contribuido a promover una visión más postiva, amable y bondadosa del ser humano.

\section{Contemplación, Neurociencia y Psicoterapia}

Comprender la naturaleza de la contemplación, ya no es competencia exclusiva de las tradiciones sapienciales. Hoy por hoy, podemos disponer de una neurociencia contemplativa. Contamos con datos de la investigación neurocientífica y eso aporta una ventaja enorme a la hora de describir y comprender los estados conscientes, sus contenidos y funciones (Josipovic y Baars, 2016). Esos datos son relevantes a la hora de hacer psicoterapia o lo que es igual a la hora de estar presente en la conversación contemplativa que la psicoterapia puede ser en el siglo XXI. Diriamos que ésta concepción de la disciplina esta en congruencia no sólo con la idea de Bauman de la modernidad líquida, también de una toma de conciencia respecto al hecho de que las narrativas/ las grandes historias de las religiones del pasado están en crisis. En realidad, empezaron a estarlo cuando triunfó la razón fría del racionalismo científico. Como dijo Rieff (1966), el homo religiosus de la pre-modernidad ha dejado paso al homo psicologicus de la post-modernidad.

\section{- La conciencia que somos versus la conciencia fenoménica}

Explicar la conciencia fenoménica no es dificil en la medida en que cada cual puede conocer fácilmente en su experiencia el sabor dulce del azucar, el calor del sol o la superficie verde de la mesa. Los cinco sentidos son cinco ventanas, a cinco tipos de universos o experiencias vividas. Explorarlas es uno de los objetivos del EAC/ULL.

Junto a las sensaciones referidas al experior, la percepción externa, tenemos también como parte de la experiencia fenoménica, la percepción interna, la interocepción y la propiocepción. Todas las prácticas contemplativas de todos los tiempos manejan la corporalidad. La ritualidad de las posturas para orar o meditar o moverse haciendo tai-chi o chi-qong, o bailando, danzando la danza de la vida, como en el sufismo.

También la conciencia mental es parte de la conciencia fenoménica, al igual que la conciencia interpersonal. En el primer caso, profundizamos en nuestro uso del lenguaje y también en el habla interna o privada y su amabilidad. La práctica de 
la Atención Consciente a los pensamientos, recuerdos, etc. contribuye a agrandar enormemente el espacio referencial de la mente, las coordenadas de la soledad o mejor dicho las cualidades de la banda sonora de la película de cada cual - reconociendo, una vez más, el carcater cinematográfico de la vida personal actual.

La Atención Consciente en el plano interpersonal contibuye a abrir una ventana a la familiarización con la instauración de estados positivos de confianza, amabilidad y resonancia afectiva, por un lado, y con la exploración de estados mentales complejos o interesantes por su negatividad u otra cosa, por otro lado.

Vale. Una vez tenemos un mapa de la conciencia fenoménica, la pregunta ineludible es ¿y eso es todo? O ¿ hay algo más? , ¿qué hay de la cuestión del yo, del yo soy? Todas las tradiciones sapienciales han hablado de una conciencia distinta a la conciencia fenoménica, que estaría siempre presente por debajo de las apariencias. A los filósofos les gusta llamarlo "Ser", a los del judaismo y el cristianismo, "Dios", a los Budistas, Naturaleza Búdica, hay muchas más opciones. En todos los casos, no obstante, lo que se postula es una naturaleza vacía de contenidos específicos o fenoménicos. Es descrita con frecuencia como pura luz o como silencio interior y, sobretodo, como algo que acontece.

Desde el punto de vista neurocientífico, se puede estudiar los estados de conciencia silenciosos. Desde el Instituto de Neurociencia de La Jolla, en California, Baars (2013) ha dado a conocer un trabajo muy interesante: "Un enfoque cientifico a la conciencia silenciosa". Esta conciencia silenciosa sería equivalente a lo que aquí hemos denominado la conciencia que somos.

La idea subyacente a las tradiciones sapienciales es que la conciencia silenciosa, la conciencia que somos existe de un modo continuo en los tres estados (vigilia, sueño y sueño profundo). Las prácticas contemplativas serían formas de facilitar la accesibilidad a esta conciencia que somos, desvelar la cortina que recubre la verdad, como decían los griegos.

El acceso a la conciencia silenciosa se interpreta con frecuencia en términos ontológicos, como una comunicación más directa (y trascendente) con el creador o como una sensación de amplitud correlativa a la conciencia oceánica de los budistas, u otros tipos de realidades metafísicas. Pero si nos atenemos a una actitud científica, tal tipo de interpretaciones no son las que corresponden ahora. Es mejor ajustarse a la evidencia empírica y ver qué se puede decir sobre los estados de conciencia silenciosa desde el punto de vista de la neurociencia. En el trabajo que comentamos, Baars se ajusta a esta tarea y pasa a desvelar los siguiente:

En el contexto neurocientífico uno de los hallazgos fundamentales fue el que alcanzó H. Benson con la meditación trancendental ( repetición continua interna y silenciosa de un mantra sonoro) que le llevaron a la formulación de la existencia de una "respuesta de relajación” que podía contrarrestar la reacción de estrés de un modo homeostático. Sin embargo, la relación entre la conciencia silenciosa y la respuesta de relajación parece que no está claramente establecida y requiere más investigación. 
Baars propone que la conciencia silenciosa se produce por un efecto de redundancia producido por las continuas repeticiones implicadas en las prácticas contemplativas, ya sea por medio de la repetición de sonidos, vistas o acciones. Esta idea tiene mucho sentido si tenemos en cuenta que los practicantes avanzados llevan cientos o miles de horas de repetición de una sílaba interior, una postura, una técnica de respiración, un gesto con la mano, etc. Los psicólogos de la Gestalt investigaron dos tipos de efectos, el efecto ganzfeld y el efecto de saciación. Ambos eran producto de la repetición y no requieren de ningún aparataje especial, de modo que pueden haber estado prresentes en las prácticas contemplativas más antiguas.

El efecto ganzfeld se produce cuando un campo visual carece de contraste temporal o espacial. La explicación parece residir en el hecho de que muchas de las neuronas visuales son sensibles al contraste y en estas condiciones deben bajar a una línea base. El brillo y la tonalidad desaparecen en los bloqueos del efecto ganzfeld, mientras la conciencia continúa. Baars (2013) cita como ejemplos los siguientes haikus de la tradición Kashimir:

1) En el verano cuando ves el cielo con una claridad sin fin, entra en esa claridad,

2) Simplemente al entrar en el cielo azul más allá de las nubes, la serenidad.

Como un cielo azul no tiene contrastes temporales o espaciales - señala Baarspodría considerarse una condición del efecto ganzfeld. En términos de la vista, las imágenes que se sostienen estables también tienen una función de redundancia. Del mismo modo, la repetición de palabras, muy utilizada en todas las prácticas contemplativas, tiene un efecto similar. Por ejemplo, la repetición de mantras es una acción sensorio-motora que, con la práctica, puede convertirse en algo que rebajaría elementos redundantes en la conciencia.

Los paracticantes describen los momentos silenciosos como momentos separados o discontinuos respecto al flujo de estimulación normal, como si fueran un hueco en el fluir de las sensaciones, las imágenes o el habla interior conscientes. En este sentido, tal vez podrían investigarse con tareas para detectar huecos.

Otro tipo de estimulación que conduce al silencio son los silencios endógenos que pueden inhibir la percepción de sonidos externos. Los sonidos biaurales, que se sienten en el centro de la cabeza, también pueden producir una situación de conciencia en silencio.

Durante los estados de silencio también se suelen reportar estados de absorción y placer. El primero hace referencia al enganche, por decirlo así, con un único flujo de pensamiento. Los silencios son descritos también como "bendiciones", lo que les añade una dimensión hedónica.

La conclusión de Baars apunta a que sabemos que la experiencia consciente implica unas oscilaciones muy extendidas en el eje cortico-talámico. Así, la conciencia silenciosa podría corresponder a un incremento del poder de las oscilaciones theta-alpha, que se extienden desde el cortex con mínimas frecuencias altas de "contenido”, como se ha reportado con frecuencia en las investigaciones con prác- 
ticas contemplativas. La metáfora última que propone el informe de Baars apunta a una analogía entre el aprendizaje de la música y el aprendizaje de las prácticas contemplativas. Ninguno de los dos es arbitrario. Y añade: Contemplative training seem designed to evoke certain conscious experiences, particularly "consciousness without content" (El entrenamiento contemplativo parece diseñado para evocar ciertas experiencias conscientes, en particular "la conciencia sin contenido") . Y termina pidiendo un método basado en principios para estudiar la psicofisica de la conciencia silenciosa momentánea (Baars, 2013, p. 95).

Además de las neurociencias, el otro punto privilegiado para explorar la naturaleza de la contemplación es la propia psicoterapia. Gracias a la proliferación de las Intervenciones Basadas en Mindfulness (IBM), la práctica de mindfulness está plenamente integrada en el tratamiento de casi cualquier trastorno, hoy por hoy. Todas las terapias de la llamada tercera generación han adoptado la práctica de mindfulness como una parte importante de la intervención. Por supuesto, también la terapia psicoanalítica o la sistémica han incorporado la práctica de mindfulness en su repertorio actual.

\section{Aplicaciones en la sesión idividual y grupal}

La práctica contemplativa formal como silencio con atención a la respiración y a la postura durante 5 minutos puede ser una forma muy beneficiosa de empezar la sesión, ya sea individual o en grupo. En los programas estandarizados de mindfulness como el MBSR o la MBCT, la sesión se comienza en silencio, practicando. Por un lado, esta forma hace posible para todos "llegar" a la sesión y, por otro, lado, sienta un ritmo tranquilo para el resto de la sesión.

La mayor parte de los problemas que atendemos en consulta, de un modo u otro, tienen que ver con la reactividad al estrés, la ansiedad o la depresión. Si paralelamente a la consulta individual, el paciente puede llevar a cabo un Entrenamiento en Atención Consciente, como el programa EAC/ULL, los tiempos del tratamiento se podrán reducir considerablemente. De cara al futuro ésta no es una cuestión baladí, porque vamos a necesitar todos los recursos disponibles para superar esta crisis y salir, como se sale de las crisis, más consciente del precioso regalo que es la vida. Y, en especial, la vita activa y la vita contemplativa.

La práctica de la Atención Consciente no es milagrosa, ni ofrece soluciones tan rápida como un ansiolítico. En cambio, a la larga, está en línea con la vida, con la vida que vale la pena vivir. En este punto, prefiero cederle la palabra al poeta Roger Keyes, que ha expresado lo que a mi me gustaría poder decir en el modo claro y sencillo de los haikus japoneses. Este poema lo escribió mientras era discípulo de un pintor japones llamado Hokusai.

"Hokusai dice mira con cuidado.

Él dice presta atención, date cuenta.

Él dice continúa mirando, ten curiosidad.

Él dice que el mirar no tiene fin. 
Él dice ten la esperanza de llegar a viejo.

Él dice sigue cambiando,

así entiendes mejor quién eres realmente.

Él dice quédate atsacado, aceptalo, repítete

siempre que sea algo interesante.

Él dice sigue haciendo lo que amas.

Él dice sigue rezando.

Él dice que cada uno de nosotros es un niño,

cada uno de nosotros es anciano,

cada uno tiene un cuerpo.

Él dice que todos tenemos miedo.

Él dice que cada uno tiene que encontrar la manera de vivir con el miedo.

Él dice que todo está vivo,

piedras, edificios, personas, peces,

montañas, árboles, la madera está viva.

El agua está viva.

Todo tiene vida propia

Él dice vive con el mundo dentro de ti.

Él dice que no importa si dibujas,

o escribes libros. No importa

si cortas madera o pescas.

No importa si te sientas en casa

y observas a las hormigas del porche

o las sombras en tu jardín.

Importa que te importe.

Importa que lo sientas.

Importa que te des cuenta.

Importa que la vida fluya a través de ti.

El goce de la vida viviendo a através de ti.

La alegría es la vida viviendo a través de ti.

La satisfacción y la fuerza

son la vida viviendo a través de ti.

La paz es la vida viviendo a través de ti.

Él dice no tengas miedo.

No tengas miedo.

Ama, siente, deja que la vida te tome de la mano.

Deja que la vida viva a través de ti.”

\section{Conclusiones}

Se ha presentado la visión de la psicoterapia como una conversación contemplativa. Como preliminar a la conversación contemplativa, se ha propuesta el Entrenamiento en Atención Consciente y se ha ofrecido un modelo en 30 sesiones 
(EAC/ULL). Se ha planteado la naturaleza ontológica de la conversación en la vida humana y se han ofrecido ejes para comprender su profundidad y alcance. También se ha abordado la investigación neurocientífica actual para acercarnos al tema de la contemplación. Por último, se han abordado cuestiones prácticas para utilizar este enfoque en la sesión terapéutica. No obstante, queda mucho trabajo por hacer para desarrollar las ideas esquematizadas aquí.

\section{Referencias bibliográficas}

Arnau, J. (2014). Manual de Filosofía portátil. Madrid, España: Atalanta.

Baars, B. J. (2013). A scientific approach to silent consciousness. Frontiers in Psychology, 4, 91-95. https://doi. org/10.3389/fpsyg.2013.00678

Feixas, G. y Miró, M. T. (1993). Aproximaciones a la Psicoterapia, una introducción a los tratamientos psicológicos. Barcelona, España: Paidós.

Illouz, E. (2010). La salvación del alma moderna, terapia emociones y la cultura de la auto-ayuda. Buenos Aires, Argentina: Katz.

Josipovic, Z. y Baars, B. J. (2016). What can Neuroscience Learn from Contemplative Practices? (pp. 6-8). Lausanne, Suiza: Frontiers Media. https://doi.org/10.3389/978-2-88919-971-6

Maturana, H. (1994). Reflexiones y conversaciones. Buenos Aires, Argentina: Editorial FU.PA.L.I.

Miró, M. T. (2018). Mindfulness en la psicoterapia actual. En M. A. Santed y S. Segovia (Eds.), Mindfulness: Fundamentos y aplicaciones (pp. 97-120). Madrid, España: Paraninfo.

Ong, W. (1984). Oralidad y Escritura. Barcelona, España: Gedisa.

Rieff, P. (1966). The triumph of the therapeutic: uses of faith after Freud. Chicago, IL: University of Chicago.

Safran, J. (2003). Introduction. En J. Safran (Ed.), Psychoanalysis and Budhism, a unfloding dialogue (pp. 1-35). Boston, MA: Wisdom Publications.

Siegel, D. (2018). Aware: the science and practice of presence. Nueva York, NY: Peguin.

Wittgesntein, L. J. J.(2017). Investigaciones filosóficas. Madrid, España: Trota (Trabajo original publicado en 1953). Zambrano, M. (1988). Persona y Democracia. Barcelona, España:Anthropos (Trabajo original publicado en 1958). 